\title{
The highly malignant phenotype of anaplastic thyroid carcinoma cell lines is recessive
}

Maria Luisa Martelli, Maria Giuseppina Miano ${ }^{1}$, Caterina Battaglia, Francesco Trapasso, Antonella Stella, Rodolfo Iuliano, Roberta Visconti ${ }^{2}$, James A Fagin ${ }^{3}$, Massimo Santoro ${ }^{2}$ and Alfredo Fusco

Dipartimento di Medicina Sperimentale e Clinica, Facoltà di Medicina e Chirurgia di Catanzaro, Università degli Studi di Catanzaro, via Tommaso Campanella 5, 88100 Catanzaro, Italy, ${ }^{1}$ Istituto dei Tumori di Napoli, via Mariano Semmola, 80131 Napoli, Italy,

${ }^{2}$ Dipartimento di Biologia e Patologia Cellulare e Molecolare, c/o Centro di Endocrinologia ed Oncologia Sperimentale del CNR, Facoltà di Medicina e Chirurgia di Napoli, Università degli Studi di Napoli 'Federico II', via Pansini, 5, 80131 Napoli, Italy, ${ }^{3}$ Division of Endocrinology and Metabolism, University of Cincinnati, College of Medicine, 231 Bethesda Avenue, Room 5564, Cincinnati, Ohio 45267, USA

(Correspondence should be addressed to Alfredo Fusco, Dipartimento di Biologia e Patologia Cellulare e Molecolare, Facoltà di Medicina e Chirurgia di Napoli, via Pansini 5, 80131 Napoli, Italy; Email: afusco@napoli.com)

\begin{abstract}
Objective: The aim of our studies was to determine whether the phenotype of the anaplastic thyroid carcinomas is dominant or recessive. In fact, it is hypothesized, on the basis of epidemiological and pathological data, that undifferentiated thyroid carcinomas are derived from differentiated tumours through a mechanism of tumour progression.

Design: Cell hybrids have been generated by cell fusion of anaplastic thyroid carcinoma cell lines, which show a highly malignant phenotype, to cell lines deriving from differentiated thyroid carcinoma, which show a non-tumorigenic or a poorly tumorigenic phenotype. All of the parental cell lines showed impaired $p 53$ gene function.

Results: The cell hybrids contained alleles from the parental cell lines. All of the cell hybrids showed a lower growth rate compared with the parental undifferentiated carcinoma cell lines and were unable to grow in soft agar and to induce tumours after injection into athymic mice.

Conclusion: Taken together, these findings suggest that the highly malignant phenotype of the anaplastic thyroid carcinoma is achieved by the impairment of gene functions that negatively regulate cell growth, rather than by the activation of dominant oncogenes.
\end{abstract}

European Journal of Endocrinology 143 515-521

\section{Introduction}

Tumours of the thyroid gland are common in humans, even though only a minority of them are malignant. Thyroid carcinomas vary considerably in aggressiveness, ranging from the non-aggressive occult papillary carcinoma to the rapidly growing anaplastic carcinoma, the latter being one of the most lethal human neoplasms. Poorly differentiated and anaplastic carcinomas seem to be derived from the progression of papillary and follicular differentiated carcinomas $(1,2)$. This progression process is expected to require multiple changes in the expression of several genes. Some of these genes may be overexpressed in the anaplastic carcinoma compared with the differentiated tumours as demonstrated for c-myc (3), galectin $(4,5), \beta-10$ thymosin (6) and HIP (7). However, it is also well known that conversion of a normal cell to a malignant one can result in the impairment of gene functions that negatively regulate cell growth (8). In fact, cell-fusion experiments implied the existence of genes provided by the non-tumorigenic cells capable of suppressing tumorigenicity (9-13). These genes are also known as tumour suppressor genes, and recessive mutations in both of the alleles are required to give the cell a growth advantage. The aim of the present work was to determine the recessive or dominant phenotype of anaplastic thyroid carcinomas through cell fusion between differentiated and anaplastic thyroid carcinoma cell lines. Therefore, cell hybrids were generated between two anaplastic thyroid carcinoma cell lines, named ARO and FRO, and two papillary (NPA and NIM1) and one follicular (WRO) carcinoma cell lines. Interestingly, NIM1 and NPA cells are derived from a differentiated and a poorly differentiated papillary carcinoma respectively. This may account for the poorly tumorigenic phenotype of the NPA cells. In contrast, FRO and ARO cells are highly neoplastic. The NIM1 and WRO cell lines are completely non-tumorigenic $(3,14-17)$. 
Here we report that the cell hybrids derived from the fusion of thyroid anaplastic and papillary or follicular carcinoma cell lines did not show the malignant phenotype, being unable to grow in agar and unable to induce tumours in athymic mice. These results suggest that the progression from differentiated to anaplastic thyroid carcinoma requires the loss of function of genes that negatively regulate thyroid cell proliferation.

\section{Materials and methods}

\section{Cell culture}

The human thyroid carcinoma cell lines used in these studies were WRO (15), NPA (16), ARO (3, 14), FRO (14) and NIM1 (17). They were grown in Dulbecco's modified Eagle's medium containing 10\% fetal bovine serum.

\section{Transfections and plasmids}

Thyroid carcinoma cell lines were transfected with the plasmids pSVneo and pSVhygro, which carry the genes for resistance to geneticin and hygromycin respectively, under the transcriptional control of the simian virus 40 (SV40) large T promoter. Transfections were performed with the calcium phosphate procedure as described (18).

\section{Cell fusion}

Cells were fused according to a published procedure (19). A mixture of $1 \times 10^{4}$ cells from both parental cell lines was seeded in a $60 \mathrm{~mm}$ dish overnight in growth medium supplemented with $10 \%$ calf serum. Cells were rinsed twice in phosphate-buffered saline and then with $4.0 \mathrm{ml} 48 \%(\mathrm{w} / \mathrm{v})$ polyethylene glycol (PEG) $\left(M_{\mathrm{r}} 1000\right)$ in serum-free medium for $45 \mathrm{~s}$. The PEG solution was removed and the cells were rinsed three times with growth medium, and then incubated overnight. The following day, the cells were transferred from the $60 \mathrm{~mm}$ dish to six $100 \mathrm{~mm}$ dishes. Selective medium containing geneticin and hygromycin was added 2 days later.

\section{Assay of the transformed state}

The tumorigenicity of the cell lines was tested by injecting $2 \times 10^{6}$ cells subcutaneously into athymic mice. The sites of injection were observed at regular intervals for the appearance of tumour formation and progression. Cell lines were considered non-tumorigenic when no evidence of tumour formation was seen by 6 months after injection. Soft-agar colony assays were performed as described elsewhere (20).

\section{Chromosomal analyses}

Chromosomal studies were performed using standard methods (21). Metaphases were stained with Giemsa and counted at low power for ploidy determination. The average number of chromosomes was determined from a minimum of 10 good metaphases.

\section{Chromosomal analysis of parental and hybrid cell lines}

Genomic DNA was isolated from both parental and hybrid cell lines by using a standard procedure (22). The DNA was used in PCR reactions with eight chromosome-specific fluorescent primers obtained from Research Genetics (Huntsville, AL, USA). Primer specificities were as follows: D1S1612 and D1S1609, chromosome 1; D3S2406, chromosome 3; D4S2394, chromosome 4; D6S1031, chromosome 6; D11S1986, chromosome 11; D12S1045, chromosome 12; GATA188F04, chromosome 21; D22S683, chromosome 22. Each $10 \mu \mathrm{l} \mathrm{PCR}$ reaction tube contained $10 \mathrm{ng}$ genomic parental or hybrid DNA, $1.5 \mathrm{mM}$ Taq Gold Buffer (Perkin-Elmer, Branchburg, NJ, USA), $250 \mathrm{mM}$ of each dNTP, $200 \mathrm{mM}$ of each ABI PRISM fluorescent primer and 0.5 U Taq Gold Polymerase (Perkin-Elmer). After the activation of Taq Gold Polymerase at $95^{\circ} \mathrm{C}$ for 15 min, 35 cycles of PCR were performed with a PerkinElmer thermal cycler 9700 at $95^{\circ} \mathrm{C}$ for $30 \mathrm{~s}$ (denaturation), at various temperatures for $30 \mathrm{~s}$ (annealing) and at $72{ }^{\circ} \mathrm{C}$ for $30 \mathrm{~s}$ (extension). PCR reaction samples were mixed with sequencing gel loading solution, heated at $95^{\circ} \mathrm{C}$ for $2 \mathrm{~min}$ and separated by electrophoresis on $5 \%$ denaturing polyacrylamide gels ( $8 \mathrm{M}$ urea) by using an automatic sequencer (ABI PRISM 377, Applied Biosystems, Foster City, CA, USA) using a CEPH (Cooperative Human Linkage Center, Research Genetics, Huntsville, AL, USA) pedigree members $1331-01$ and $1331-02$ as standards.

\section{RNA isolation and Northern blot analysis}

RNA was extracted from the parental and hybrid cells by using previously described procedures (22). Northern blots and hybridizations have been described previously (3). The c-myc probe used in this study was the $1.3 \mathrm{~kb}$ PstI-PstI fragment of the pRyc 7.4 plasmid, which is specific for the human myc gene (3). A mouse $\beta$-actin probe was used to ascertain equal RNA loading (3).

\section{Results}

\section{Features of the parental thyroid carcinoma cell lines and production of thyroid carcinoma cell hybrids}

The characteristics of the parental thyroid carcinoma cell lines are summarized in Table 1. ARO and FRO are highly tumorigenic: in fact, they grow with good efficiency in soft agar and are able to induce invasive tumours with a short latency period in athymic mice. 
Table 1 Human thyroid carcinoma cell lines and fusion combinations for generation of hybrid cell lines.

\begin{tabular}{|c|c|c|c|c|c|c|c|}
\hline Cell lines & Histotype & $\begin{array}{c}\text { Chromosomes } \\
\text { (average) }\end{array}$ & $\begin{array}{c}\text { Chromosomes } \\
\text { (range) }\end{array}$ & $\begin{array}{l}\text { Doubling } \\
\text { time (h) }\end{array}$ & $\begin{array}{c}\text { Agar } \\
\text { growth }\end{array}$ & $\begin{array}{c}\text { Tumour } \\
\text { incidence }^{\mathrm{a}}\end{array}$ & $\begin{array}{l}\text { Latency period } \\
\text { (weeks) }\end{array}$ \\
\hline \multicolumn{8}{|l|}{ Parental line } \\
\hline ARO & Anaplastic & 65 & $60-71$ & 6 & +++ & $5 / 5$ & $2-3$ \\
\hline FRO & Anaplastic & 75 & $68-79$ & 10 & ++ & $5 / 5$ & $2-3$ \\
\hline NIM & Papillary & 92 & $87-96$ & 16 & - & $0 / 5$ & - \\
\hline NPA & Papillary $^{c}$ & 57 & $50-61$ & 24 & + & $3 / 5$ & $8-10$ \\
\hline WRO & Follicular & 81 & $77-88$ & 24 & - & $0 / 5$ & - \\
\hline \multicolumn{8}{|l|}{ Hybrid line } \\
\hline ARO-ARO & l & - & & 6 & +++ & $5 / 5$ & $2-3$ \\
\hline FRO-FRO & I & 109 & $101-119$ & 10 & ++ & $5 / 5$ & $2-3$ \\
\hline WRO-NPA & / & 137 & $130-143$ & 19 & - & $0 / 5$ & - \\
\hline WRO-ARO & / & 127 & $122-134$ & 16 & - & $0 / 5$ & - \\
\hline WRO-FRO & l & 97 & $90-104$ & 28 & - & $0 / 5$ & - \\
\hline FRO-NIM & l & 109 & $99-112$ & 15 & - & $0 / 5$ & - \\
\hline
\end{tabular}

${ }^{\text {a }}$ Subconfluent dishes were trypsinized, centrifuged and resuspended in serum-free media to $10^{7}$ cells $/ \mathrm{ml}$. Cells $\left(5 \times 10^{6}\right)$ were injected s.c. under each haunch of nu/nu mouse. Incidence is represented by the number of tumours that developed relative to total sites injected. Complete absence of tumour formation was scored after 200 days.

${ }^{\mathrm{b}}$ The latency period is the time from injection until the tumour was first palpable.

${ }^{c}$ Poorly papillary differentiated carcinoma.

Conversely, WRO and NIM1 are not able to grow in agar and are not tumorigenic in athymic mice. The NPA cells present intermediate behaviour, showing the ability to grow in a semi-solid medium, albeit at low efficiency, and to give rise to small tumours (3). To generate cell hybrids between carcinoma thyroid cell lines, each cell line was transfected with the plasmids pSVneo or pSVhygro, which carry the genes for resistance to geneticin and hygromycin respectively. The cells were selected in media containing the selecting drug. Several clones and the pool population were picked up for each transfection. Subsequently, fusions were performed between different cell lines selecting the hybrid cells in a medium containing both geneticin and hygromicin. In this case also, several clones and the pool populations were picked up. Three clones and the pool population were further analysed for growth rate, growth in soft agar and tumorigenicity. The results presented here refer to one representative cell clone; however, similar results were obtained with all of the clones derived from the same cell fusion. The five cell lines and the four fusion combinations are described in Table 1.

\section{Cytogenetic characterization}

All of the hybrid lines were examined for their chromosomal composition to confirm that they were true hybrids. The chromosomal features of both hybrids and parental lines are summarized in Table 1 . These results provide firm evidence that the cell lines were really hybrids. In fact, they always contained more chromosomes of the parental cell lines. The parental tumour lines are mostly hypotriploid, whereas the hybrid cell lines are mostly hypotetraploid or hypopentaploid. In some cases, the number of chromosomes in the hybrids corresponded to the sum of the chromosome numbers of the parental cell lines (see the WRO-NPA cell hybrid).

Moreover, to obtain further verification that the cell lines recovered after fusion and selection in G418hygromicin medium were actually hybrids of the parental cell lines, we used pairs of PCR primers that span highly polymorphic sequences on specific chromosomes $(23,24)$. Primer pairs were first screened to identify those that yelded size polymorphisms in the different cell lines; then genomic DNA, isolated from each of the hybrid cell lines and from the parental cells, was amplified by PCR with these pairs of primers. The analysis of PCR products obtained with eight primer pairs representing different chromosome microsatellites is summarized in Table 2. Entries in Table 2 show the sizes (in nucleotides) of the products obtained, indicating which alleles are present. They indicated that the hybrids contained alleles from both parental cell lines.

Therefore, although not all of the chromosomes were analysed, the results demonstrate that the selected cell lines represent true hybrids between the two parental cell lines.

\section{Morphology and growth rate of the cell hybrids}

In Fig. 1, we show the morphology of the parental cell lines and the cell hybrids. Generally, the morphology of the cell hybrids was different from that of both parental cell lines. The hybrids generated from the ARO cell line lost the round shape typical of the ARO cells and showed greater adhesion to the plate, suggesting a reduced malignant phenotype.

The growth rate of the hybrid lines was determined (see the results reported in Table 1). The hybrid cells showed a growth-rate reduction that is particularly 
Table 2 Analysis of selected chromosomes of parental and hybrid cell lines.

\begin{tabular}{lccccccccc}
\hline & \multicolumn{10}{c}{ Product size (nucleotides) $^{\mathrm{b}}$} \\
\cline { 2 - 11 } Marker & ARO & WRO & NIM & NPA & FRO & WRO-NPA & WRO-ARO & WRO-FRO & FRO-NIM \\
\hline 1 (D1S1612) & 110,122 & 118 & 96,122 & 96,126 & 118,126 & $96,118,126$ & $118,122,110$ & 118,126 & $118,122,126$ \\
1 (D1S1609) & 180,200 & 204 & 204 & 200 & 184,200 & 200,204 & $180,204,200$ & 184,200 & $184,200,204$ \\
3 (D3S2406) & 334,338 & 334,346 & 338,354 & 334,350 & 322,350 & $334,346,350$ & 338,346 & $334,346,350$ & $322,354,338$ \\
4 (D4S2394) & 238 & 238,250 & 241 & 256 & 241 & $238,250,256$ & 238,250 & $238,241,250$ & 241 \\
6 (D6S1031) & 248,264 & 264 & 248,261 & 248,264 & 248,258 & 248,264 & 264,248 & $248,258,264$ & 248,261 \\
11 (D11S1986) & 196,228 & 192,240 & 196,204 & 192,248 & 232,240 & $192,240,248$ & $192,196,228,240$ & $192,232,240$ & $196,204,232,240$ \\
12 (D12S1045) & 76,80 & 92 & 94,76 & 88,92 & 92,94 & 88,92 & 76,92 & 92,94 & $92,94,76$ \\
21 (GATA188F04) & 125,131 & 193 & 117,193 & 117,157 & 129,157 & $117,157,193$ & 193,131 & $129,157,193$ & $129,157,193$ \\
22 (D22S683) & 176,204 & 180 & 168,172 & 168,172 & 176 & $168,172,180$ & 180,204 & 176,180 & 168,176 \\
\hline
\end{tabular}

${ }^{a}$ Markers were primer pairs (identified in parentheses) that are specific for each of the indicated chromosomes.

${ }^{\mathrm{b}}$ Chromosomal DNA was isolated from each of the indicated parental and hybrid cell lines, and PCR reactions were carried out using the indicated primer pairs. Reaction products were separated on DNA sequencing gels. Entries in the table show the size (in nucleotides) of the products obtained, indicating which alleles were present.

striking for the FRO-WRO hybrid, which showed a growth rate $(28 \mathrm{~h})$ even lower than that of the WRO cells $(24 \mathrm{~h})$. No changes in the cell growth and morphology of the parental-parental self-hybrids (i.e. FRO-FRO, AROARO and NPA-NPA) in comparison to the respective parental cell lines were observed (data not shown), thus excluding the possibility that the slower growth of hybrid cells was solely dependent on the fusion process.

\section{Analysis of the malignant phenotype of hybrids}

All the hybrid cells were found to be unable to grow efficiently in soft agar and to be unable to give rise to tumours when injected into athymic mice (Table 1). Conversely, the FRO-FRO and ARO-ARO cells grew efficiently in soft agar and were highly tumorigenic in athymic mice.

Therefore, the fusion of the anaplastic thyroid cell lines with papillary and follicular cell lines results in the suppression of the malignant phenotype. Interestingly, even the fusion of the poorly tumorigenic and poorly differentiated carcinoma NPA cells with the follicular carcinoma cell line WRO gives rise to a hybrid cell line that is unable to grow in soft agar, unable to induce tumours in athymic mice and which has a reduced growth rate relative to the parental cell lines; this indicates that a tumour suppressor gene may be involved in the progression step driving the cells from a differentiated carcinoma to a poorly differentiated papillary carcinoma. We also evaluated the expression of genes, such as c-myc, correlated with the aggressive phenotype (3) in hybrid cells: they were expressed at lower levels compared with the parental anaplastic cell lines (data not shown).

\section{Discussion}

Malignant tumours of the thyroid gland include differentiated and undifferentiated carcinomas. The latter are probably derived from the progression of the former ones $(1,2)$. It can be assumed that the anaplastic phenotype of thyroid tumours may be achieved through the acquisition of the ability to express genes involved in tissue invasion or cell proliferation and/or the inactivation or deletion of tumour suppressor genes. Alterations in the p53 tumour suppressor gene have been described as a peculiar feature of the anaplastic carcinomas (25). However, from the data present in the literature, deletion or mutations of the $p 53$ gene do not seem to be the only alteration present in anaplastic carcinomas. In fact, thyroid tumours do not appear in LiFraumeni patients and p53 null mice, suggesting that other genes $(26,27)$ (oncogenes or suppressor genes) may be involved in the process of carcinogenesis leading to the anaplastic phenotype. To date, the oncogenes that have been found activated in human thyroid tumours, such as RET/PTC and TRK, have never been found associated with p53 mutations (25) and Ras mutations have been found only in two cases associated with mutations in the $p 53$ gene (28).

Even in vitro co-operation between activated ras and mutated p53 genes does not lead to the achievement of the neoplastic phenotype in thyroid cells (F. Trapasso and A. Fusco, manuscript in preparation). Moreover, loss of heterozygosity on chromosome 10q22 has been observed in two follicular carcinomas adjacent to an area of anaplastic carcinomas $(29,30)$. These data would support the involvement of other suppressor genes in the progression process leading to the anaplastic phenotype. To validate this hypothesis, hybrid cell lines were generated by the fusion of cell lines originating from thyroid undifferentiated carcinomas with those originating from differentiated carcinomas, including the papillary and the follicular histotype. Cytogenetic studies of the hybrid lines confirm that they were true hybrids. In fact, they contain more chromosomes than the parental cell lines (in some cases, the chromosome number was close to 


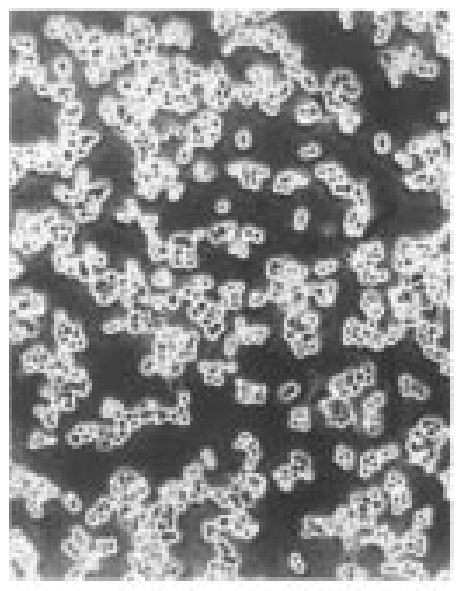

ARO

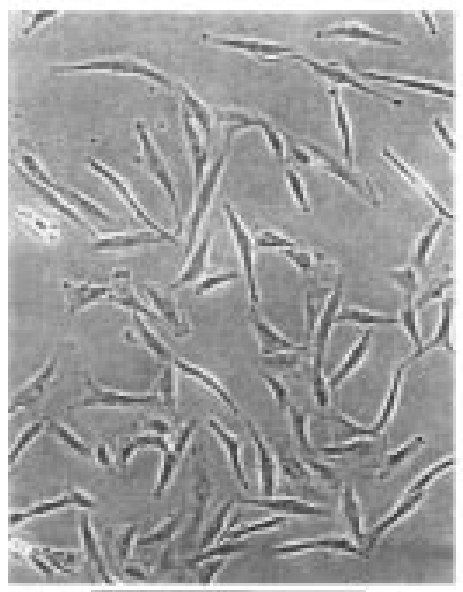

WRO

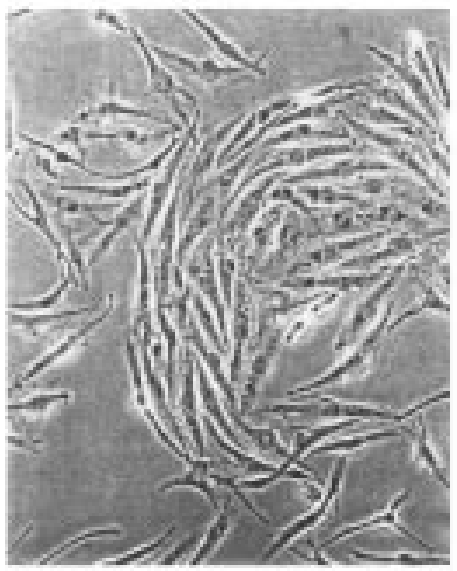

FRO-WRO

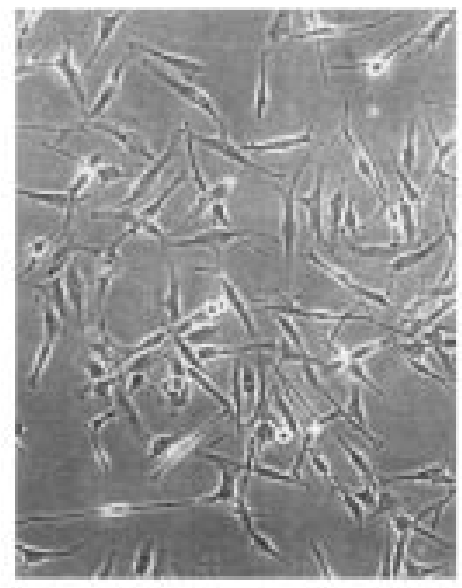

FRO

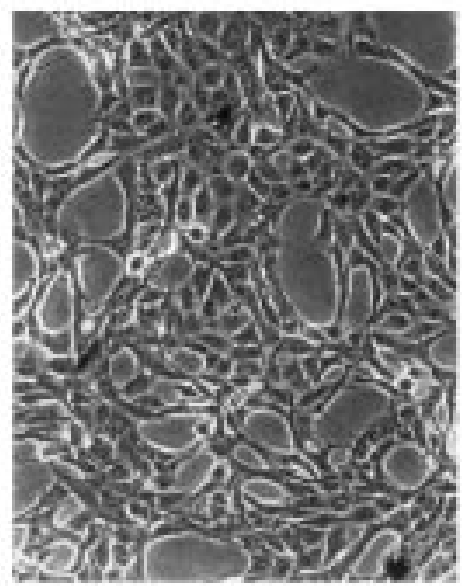

NIM

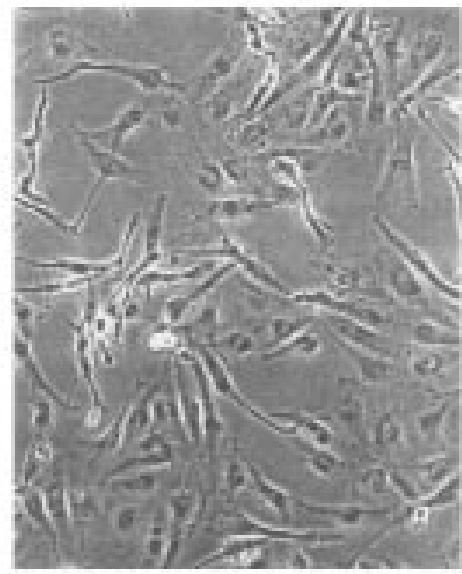

FRO-NIM

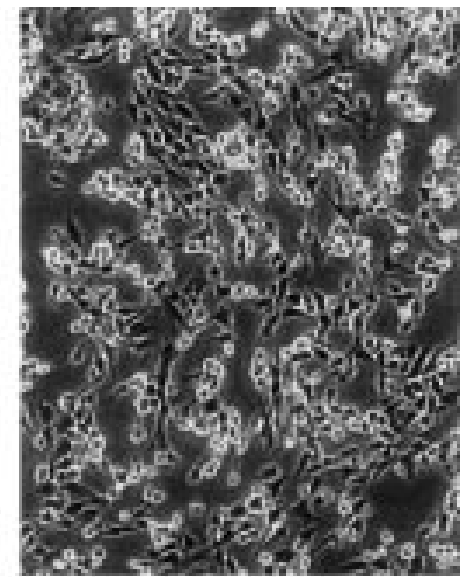

NPA

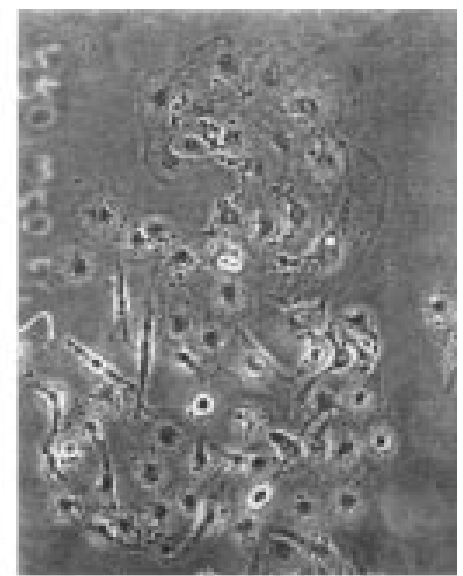

ARO-WRO

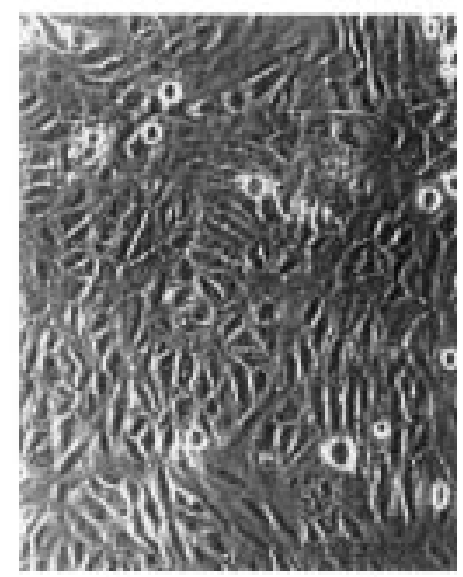

NPA-WRO

Figure 1 Phase-contrast photomicrographs of parental and hybrid cell lines. Magnification: $150 \times$. 
the sum of those of the fusion partners). Moreover, the analysis of polymorphic sites showed that the hybrids retained the alleles of both parental cells.

The results reported here provide evidence that the loss of some genes is required for progression towards the anaplastic thyroid phenotype. In fact, the hybrids showed the abolition of the markers of malignancy, such as growth in agar and tumorigenicity in athymic mice. Furthermore, these hybrids were less spindle-shaped, there was an increase in adhesiveness to cell plates and there was a reduction in the growth rate. In this report, we also show that the hybrid NPA-WRO is not tumorigenic: this might indicate that the poorly tumorigenic phenotype of a poorly differentiated papillary carcinoma might be correlated wth the loss of some tumour suppressor activity.

The possibility of the involvement of the $p 53$ wild type in the suppression of the malignant phenotype of the hybrids can be excluded since all of the parental cell lines show impaired p53 gene function (14), which represents a feature of all the established thyroid carcinoma cell lines that is independent of histotype. In fact, ARO, WRO and NPA showed mutations in the p53 gene at codons 273, 223 and 266 respectively, whereas the FRO cell line showed a drastic reduction in p53-specific mRNA expression (14). Moreover, analysis of the hybrids revealed the presence of the mutated p53 proteins (data not shown). Therefore, changes in the expression of the malignant phenotype by the cell hybrids can be considered to be independent of the presence of a wildtype $\mathrm{p} 53$ protein.

In conclusion, the data reported here imply the presence in papillary and follicular carcinoma cells of genes able to block the aggressiveness of the anaplastic thyroid carcinoma cell lines, suggesting that the same genes were somehow inactivated in the original tumour. Moreover, the cell hybrids reported here may represent an excellent cell-based system for the identification of genes (probably tumour suppressor genes) involved in human thyroid carcinogenesis.

\section{Acknowledgements}

This work has been supported by the Fondo Sanitario Nazionale 1994 from the Ministero della Sanità, Italy and by grants from the AIRC (Progetto Speciale Oncosoppressori), the Progetto Finalizzato 'ACRO', the Progetto Finalizzato 'Biotecnologie' of the CNR and the MURST project 'Terapie Antineoplastiche Innovative'. Francesco Trapasso and Antonella Stella were recipients of fellowships from the Fondazione Italiana per la Ricerca sul Cancro (FIRC). This work was supported by grants from the AIRC (Progetto Speciale Oncosoppressori). Alfredo Fusco was the recipient of the Yamagiwa-Yoshida Memorial International Cancer Study Grant of the UICC.

\section{References}

1 Williams ED. The aetiology of thyroid tumors. Journal of Clinical Endocrinology and Metabolism 19798 193-207.

2 Hedinger C, Williams ED \& Sobin, LH. The WHO histological classification of thyroid tumors: a commentary on the second edition. Cancer 198963 908-911.

3 Cerutti J, Trapasso F, Battaglia C, Zhang L, Martelli ML, Berlingieri MT et al. Blockage of c-MYC protein synthesis in human thyroid carcinoma cell lines reduces their growth in soft agar. Clinical Cancer Research 19962 119-126.

4 Chiariotti L, Berlingieri MT, Berger N, De Rose P, Battaglia C, Bruni CB \& Fusco A. Increased expression of the negative growth factor, galactoside binding protein gene in transformed thyroid cells and in human thyroid carcinomas. Oncogene $199372507-$ 2511.

5 Chiariotti L, Berlingieri MT, Battaglia C, Benvenuto G, Martelli ML, Salvatore $\mathrm{P}$ et al. Galectin-1 expression is increased in papillary and undifferentiated thyroid carcinoma histotypes. International Journal of Cancer 199564 171-175.

6 Califano D, Monaco C, Santelli G, Giuliano A, Veronese ML, Berlingieri MT et al. Thymosin B-10 gene overexpression correlates with the highly malignant neoplastic phenotype of transformed thyroid cells in vivo and in vitro. Cancer Research 1998 $58823-828$.

7 de Nigris F, Visconti R, Cerutti J, Califano D, Mineo A, Fagin JA et al. Overexpression of the HIP gene coding for a heparin/heparan sulfate-binding protein in human thyroid carcinomas. Cancer Research 199858 4745-4751.

8 Fearon ER. Tumor suppressor genes. In Controls on Cell Growth in the Genetic Basis of Human Cancer, vol 2, pp 229-240. Eds B Vogelstein \& KW Kinzler. New York: McGraw-Hill, 1998.

9 Craig RW \& Sager R. Suppression of tumorigenicity in hybrids of normal and oncogene-transformed CHEF cells. PNAS 199582 $2062-2066$.

10 Stanbridge EJ, Der CJ, Doerson CJ, Nishimi RY, Peehl DM, Weissman BE \& Wilkinson JE. Human cell hybrids: analysis of transformation and tumorigenicity. Science 1982215 252-259.

11 Harris $\mathrm{H}$. The analysis of malignancy by cell fusion: the position in 1988. Cancer Research 198848 3302-3306.

12 Klinger HP \& Kaelbing M. Suppression of tumorigenicity in somatic cell hybrids. IV. Chromosomes of normal human cells associated with suppression of tumorigenicity in hybrids with D98AH2 carcinoma cells. Cytogenetics and Cell Genetics 198642 226-236.

13 Weissman H \& Stanbridge EJ. Complementation of the tumorigenic phenotype in human cell hybrids. Journal of the National Cancer Institute 198370 667-672.

14 Fagin JA, Matsuo K, Karmakar A, Chen DL, Tang SH \& Koeffier HP. High prevalence of mutations of the $\mathrm{p} 53$ gene in poorly differentiated human thyroid carcinomas. Journal of Clinical Investigation 199391 179-184.

15 Estour AJ, Van Herle GJF, Juillard TL, Totanes RS, Sparkes AE, Giuliano J \& Klandorf $\mathrm{H}$. Characterization of a human follicular thyroid carcinoma cell line (UCLA RO $82 \mathrm{~W}-1$ ). Virchows Archiv B Cell Pathology including Molecular Pathology 198957 167-174.

16 Pang XJ, Hershman M, Chung M \& Pekary AE. Characterization of tumor necrosis factor-alpha receptors in human and rat thyroid cells and regulation of the receptors by thyrotropin. Endocrinology $19891251783-1788$.

17 Zeki K, Nakano Y, Inokuchi N, Watanabe K, Morimoto I, Yamashita U \& Eto S. Autocrine stimulation of interleukin-1 in the growth of human thyroid carcinoma cell line NIM1. Journal of Clinical Endocrinology and Metabolism 199176 127-133.

18 Graham FL \& Van der Eb AJ. A new technique for the assay of the infectivity of human adenovirus 5 DNA. Virology 197352 456467.

19 Davidson RL \& Gerald PS. Improved techniques for the induction of mammalian cell hybridization by polyethylene glycol. Somatic Cell Genetics 19762 165-176. 
20 Macpherson I \& Montagnier I. Agar suspension culture for the selective assay of cells transformed by Polyoma virus. Virology 196423 291-294.

21 Peterson WD Jr, Simpson WF \& Hukku B. Cell culture characterization: monitoring for cell identification. In Methods in Enzymology, pp 164-178. Eds WB Jakoby \& IH Pastant. New York: Academic Press, 1979.

22 Sambrook J, Fritsch EF \& Maniatis T. Molecular Cloning: A Laboratory Manual. Cold Spring Harbor, New York: Cold Spring Harbor Laboratory, 1989.

23 Hudson TJ, Engelstein M, Lee MK, Ho EC, Rubenfield MJ, Adams CP, Housman DE \& Dracopoli NC. Isolation and chromosomal assignment of 100 highly informative human simple sequence repeat polymorphisms. Genomics 199213622 629.

24 Ess K, Chen H, Kier A \& Brackenbury R. Suppression of tumorigenicity, but not invasion, in glioblastoma/HeLa cell hybrids. Journal of Cell Physiology 1995162 341-347.

25 Santoro M, Grieco M, Melillo RM, Fusco A \& Vecchio G. Molecular defects in thyroid carcinomas: role of the RET oncogene in thyroid neoplastic transformation. European Journal of Endocrinology 1995 $133513-522$.
26 Li FP, Fraumeni JF Jr, Mulvihill JJ, Blattner WA, Dreyfus MG, Tucker MA \& Miller RW. A cancer family syndrome in twenty-four kindreds. Cancer Research 198848 5358-5362.

27 Donehower LA, Harvey M, Slagle BL, McArthur M, Oyama T, Montgomery CA, Butel JS \& Bradley A. Mice deficient for p53 are developmentally normal but susceptible to spontaneous tumours. Nature 1992356 215-221.

28 Salvatore D, Battaglia C, Trapasso F, Martelli ML, Viglietto G, Califano D et al. Low frequency of p53 mutations in human thyroid tumors; p53 and ras mutation in two out of fifty-six thyroid carcinomas. European Journal of Endocrinology 1996134 177-183.

29 Zedenius J, Wallin G, Svensson A, Grimelius L, Hoog A, Lundell B, Backdahl M \& Larsson C. Allelotyping of follicular thyroid tumors. Human Genetics 199696 27-32.

30 Zedenius J, Wallin G, Svensson A, Bovee J, Hoog A, Backdahl M \& Larsson C. Deletions of the long arm of chromosome 10 in progression of follicular thyroid tumors. Human Genetics 199697 299-303.

Received 16 March 2000

Accepted 13 June 2000 